\title{
Studies on crystallization behaviour and mechanical properties of Al-Ni-La metallic glasses
}

\author{
K L SAHOO*, RINA SAHU, M GHOSH and S CHATTERJEE ${ }^{\dagger}$ \\ Metal Extraction and Forming Division, National Metallurgical Laboratory, Jamshedpur 831 007, India \\ ${ }^{\dagger}$ Department of Metallurgical and Materials Engineering, Bengal Engineering and Science University, \\ Howrah 711 103, India
}

\begin{abstract}
Alloy ingots with nominal composition, $\mathrm{Al}_{92-x} \mathrm{Ni}_{8} \mathrm{La}_{x}(x=4$ to 6$)$ and $\mathrm{Al}_{94-x} \mathrm{Ni}_{6} \mathrm{La}_{x}(x=6,7)$, were prepared by induction melting in a purified Ar atmosphere. Each ingot was inductively re-melted and rapidly solidified ribbons were obtained by ejecting the melt onto a rotating copper wheel in an argon atmosphere. The crystallization behaviour of melt-spun amorphous ribbon was investigated by means of differential scanning calorimetry (DSC), X-ray diffractometry and transmission electron microscopy. DSC showed that $\mathrm{Al}_{86} \mathrm{Ni}_{8} \mathrm{La}_{6}$ alloy undergoes a three-stage and rest of the alloys undergo a two-stage crystallization process upon heating. The phases responsible for each stage of crystallization were identified. During the first crystallization stage $f c c$-Al precipitates for low La-containing alloys and for higher La-containing alloys a bcc metastable phase precipitates. The second crystallization stage is due to formation of intermetallic compounds along with $f c c$ Al. Microhardness of all the ribbons was examined at different temperatures and correlated with structural evolutions. Precipitation strengthening of nano-size $f c c-\mathrm{Al}$ is responsible for maximum hardness in these annealed alloys.
\end{abstract}

Keywords. Metallic glass; Al-Ni-La alloys; XRD; crystallization.

\section{Introduction}

Increasing demand for high performance engineering components continuously drives the development of new advanced materials. Amorphous and nanocrystalline alloys are examples of such materials. Al-based amorphous alloys have attracted considerable attention in the last two decades due to the occurrence of a primary crystallization reaction that yields a microstructure consisting of uniformly dispersed Al-nanocrystals embedded in an amorphous matrix. These alloys possess high specific strength coupled with good ductility, high hardness, and good wear and corrosion resistance. However, these favourable properties fall off if the alloys crystallize to a grain size that exceeds the nanometre range. Growth of these nano-crystals could be retarded by choosing alloy composition, which lead to higher activation energy of crystallization and/or introduce a thermal barrier for crystallization (Inoue 1998).

Among the Al-based amorphous alloys, Al-Ni-RE $(\mathrm{RE}=\mathrm{Y}$, or rare-earth elements) with $\mathrm{Al}$ content between 80 and 90 at.\% have attracted considerable attention due to their wide glass formation ranges. By partial crystallization, one can tailor alloy properties that are an important prerequisite for its use as an advanced engineering material. Gangopadhyay and Kelton (2000) investigated

*Author for correspondence (klsah@nmlindia.org) the crystallization process in $\mathrm{Al}-\mathrm{Ni}-\mathrm{RE}$ amorphous alloys and found that crystallization products depend on the radius of the rare-earth atoms. They showed that alloys containing smaller radius $\mathrm{RE}$ elements produce $f c c-\mathrm{Al}$ while larger radius $\mathrm{RE}$ elements produce metastable intermetallic phases as primary crystallization product. In contrast, Gogebakan et al (1997) reported that the first crystallization products in $\mathrm{Al}_{85} \mathrm{Ni}_{4} \mathrm{Y}_{11}$ are $f c c-\mathrm{Al}, \mathrm{Al}_{3} \mathrm{Y}$ and some unidentified metastable intermetallic phases. The formation of a $f c c-A l$ phase after the first crystallization stage was reported by $\mathrm{Ye}$ and $\mathrm{Lu}$ (1999) in $\mathrm{Al}_{89} \mathrm{Ni}_{5} \mathrm{La}_{6}$ and Sahoo et al (2004) in $\mathrm{Al}_{90} \mathrm{Ni}_{6} \mathrm{La}_{4}$, whereas Zhuang et al (2001) reported eutectic crystallization of $f c c-\mathrm{Al}$ and metastable $b c c-(\mathrm{AlNi})_{11} \mathrm{La}_{3}$-like phase in $\mathrm{Al}_{89} \mathrm{Ni}_{5} \mathrm{La}_{6}$ alloy. No systematic report is available on the nature of crystallization product in $\mathrm{Al}-\mathrm{Ni}-\mathrm{La}$ alloys.

In this present paper, the thermal stability, crystallization pathways and evolution of microhardness of Al-Ni-La amorphous alloys containing 6 and 8 at.\% $\mathrm{Ni}$ and varying amounts of La are investigated. Microstructural evolution of alloys with temperature is correlated with the microhardness.

\section{Experimental}

Ingots with compositions, $\mathrm{Al}_{88} \mathrm{Ni}_{8} \mathrm{La}_{4}$ (A84), $\mathrm{Al}_{87} \mathrm{Ni}_{8} \mathrm{La}_{5}$ (A85), $\mathrm{Al}_{86} \mathrm{Ni}_{8} \mathrm{La}_{6}$ (A86), $\mathrm{Al}_{88} \mathrm{Ni}_{6} \mathrm{La}_{6}$ (A66) and $\mathrm{Al}_{87} \mathrm{Ni}_{6} \mathrm{La}_{7}$ (A67), were prepared by alloying pure components (puri- 
ties were $5 \mathrm{~N} \mathrm{Al} ; 4 \mathrm{~N} \mathrm{Ni}$; $3 \mathrm{~N} \mathrm{La}$ ) by induction melting under a purified argon atmosphere (purity: $99.999 \%$ ). The ingot was inductively re-melted (temperature ranges from $1280-1300 \mathrm{~K}$ ) and melt-spun ribbons were prepared by ejecting the melt onto a rotating copper wheel (rotational speed: $40 \mathrm{~m} / \mathrm{s}$ ) in He atmosphere.

The amorphous nature of the as-prepared ribbons was proved by XRD (Siemens, $40 \mathrm{kV}, 40 \mathrm{~mA}, \mathrm{CuK}_{\alpha}$, scan rate $0.15^{\circ} \mathrm{min}^{-1}$ ) and TEM (Philips CM200). The crystallization behaviour of the ribbons was studied by DSC (DSC-7, Perkin-Elmer) under a high purity argon atmosphere. The DSC was calibrated by using pure In and $\mathrm{Zn}$ standards, giving an accuracy of $\pm 0.3 \mathrm{~K}$ for temperature and $\pm 0.02 \mathrm{~mW}$ for the heat flow measurements. The isochronal DSC study was conducted at different heating rates ranging from $10-40 \mathrm{~K} / \mathrm{min}$. For scanning at a constant heating rate, a second scan was used as a base line. The TEM samples were prepared by electrochemical dissolution method using a solution of $25 \%$ nitric acid and $75 \%$ methanol at $243 \mathrm{~K}$ and $12 \mathrm{~V}$. The evolution of hardness with temperature was investigated using a Paar Physica microhardness tester (MHT-10, Anton Paar) under a $0 \cdot 2 \mathrm{~N}$ load.

\section{Results}

\subsection{XRD studies}

The ribbons prepared by melt spinning are $30 \pm 5 \mu \mathrm{m}$ in thickness, 1-2 mm wide and several meters long. All the ribbons show good bend ductility. XRD patterns revealed that all the melt-spun ribbons were fully amorphous on the substrate side (not shown) as well as on the air-cooled side (figure 1). All the as-quenched samples showed a distinct broad and a small diffuse maximum centred around $37^{\circ}$ and $66^{\circ}$, respectively which are characteristics

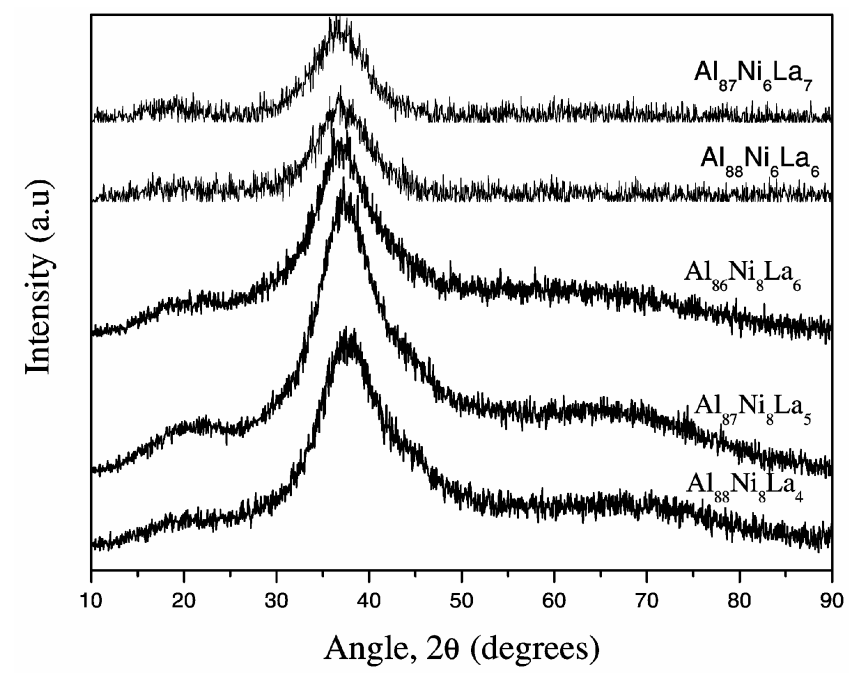

Figure 1. XRD patterns of as-melt-spun Al-Ni-La amorphous ribbons on the air-cooled side. of a glassy phase. In addition to these diffuse maxima, a small pre-peak at $2 \theta=15-24^{\circ}$ exists in all the ribbons.

\subsection{DSC studies}

The ribbons are heated continuously in DSC at heating rates varying from $10-40 \mathrm{~K} / \mathrm{min}$. Figure 2 represents the DSC curves of the amorphous alloys heated at a rate of $40 \mathrm{~K} / \mathrm{min}$. The influence of alloy composition on the heat effects and their positions is revealed in figure 2. Two or three exothermic peaks corresponding to the crystallization of the phases are observed in different temperature ranges. The peak temperature for crystallization and the activation energy for the formation of phases are shown in table 1 . The first $T_{\mathrm{p}}$ increases whereas the second $T_{\mathrm{p}}$ decreases with higher La content. The onset and peak temperatures of the crystallizations are shifted towards higher temperatures when the heating rate is raised except for the A86 alloy where the second crystallization temperature decreases with increasing heating rate. This is due to appearance of the third peak. The activation energy $\left(E_{\mathrm{a}}\right)$ of the crystallization stages are determined by Kissinger (1957) analysis

$$
\ln \left(\frac{T_{\mathrm{p}}^{2}}{\beta}\right)=\left(\frac{E_{\mathrm{a}}}{R T_{p}}\right)+A,
$$

where $\beta$ is the heating rate, $T_{\mathrm{p}}$ the peak temperature in Kelvin, $R$ the gas constant and $A$ a constant. The values of activation energies for all crystallization stages are shown in table 1.

In order to identify the phases responsible for the crystallization stages in the DSC curve, different samples

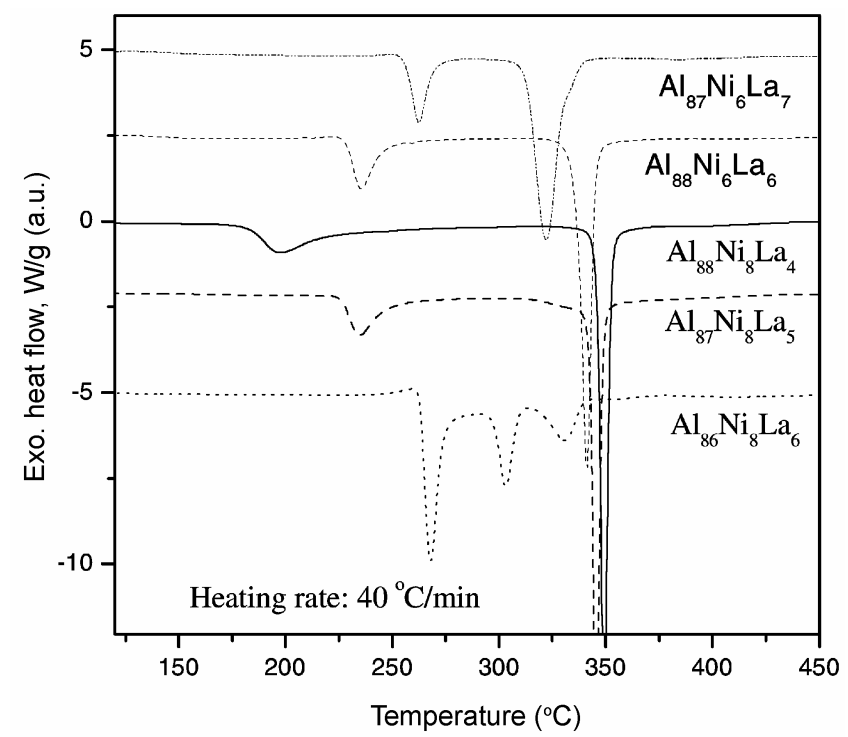

Figure 2. Continuous heating of DSC curves of amorphous Al-Ni-La alloys at a heating rate of $40 \mathrm{~K} / \mathrm{min}$. 
Table 1. Peak temperatures at different heating rates and activation energy for the different stages of crystallization.

\begin{tabular}{lcccccc}
\hline & & \multicolumn{3}{c}{ Peak temperature $\left({ }^{\circ} \mathrm{C}\right)$ at different heating rates } & \\
\cline { 3 - 5 } Alloy system & Crystallization stages & $10 \mathrm{~K} / \mathrm{min}$ & $20 \mathrm{~K} / \mathrm{min}$ & $30 \mathrm{~K} / \mathrm{min}$ & $40 \mathrm{~K} / \mathrm{min}$ & \multirow{2}{*}{$E_{\mathrm{a}}(\mathrm{kJ} / \mathrm{mol})$} \\
\hline A66 & 1st peak & 224 & 230 & 233 & 236 & $257 \pm 7$ \\
& 2nd peak & 321 & 331 & 337 & 341 & $194 \pm 1$ \\
A67 & 1st peak & 246 & 256 & 262 & 267 & $148 \pm 6$ \\
& 2nd peak & 309 & 317 & 321 & 323 & $355 \pm 12$ \\
A84 & 1st peak & 186 & 192 & 195 & 197 & $207 \pm 12$ \\
A85 & 2nd peak & 329 & 339 & 345 & 349 & $200 \pm 1$ \\
& 1st peak & 224 & 229 & 232 & 235 & $258 \pm 7$ \\
A86 & 2nd peak & 325 & 335 & 341 & 345 & $201 \pm 1$ \\
& 1st peak & 255 & 261 & 265 & 268 & $253 \pm 16$ \\
& 2nd peak & 306 & 305 & 304 & 303 & - \\
& 3rd peak & - & 317 & 326 & 331 & $164 \pm 8$ \\
\hline
\end{tabular}
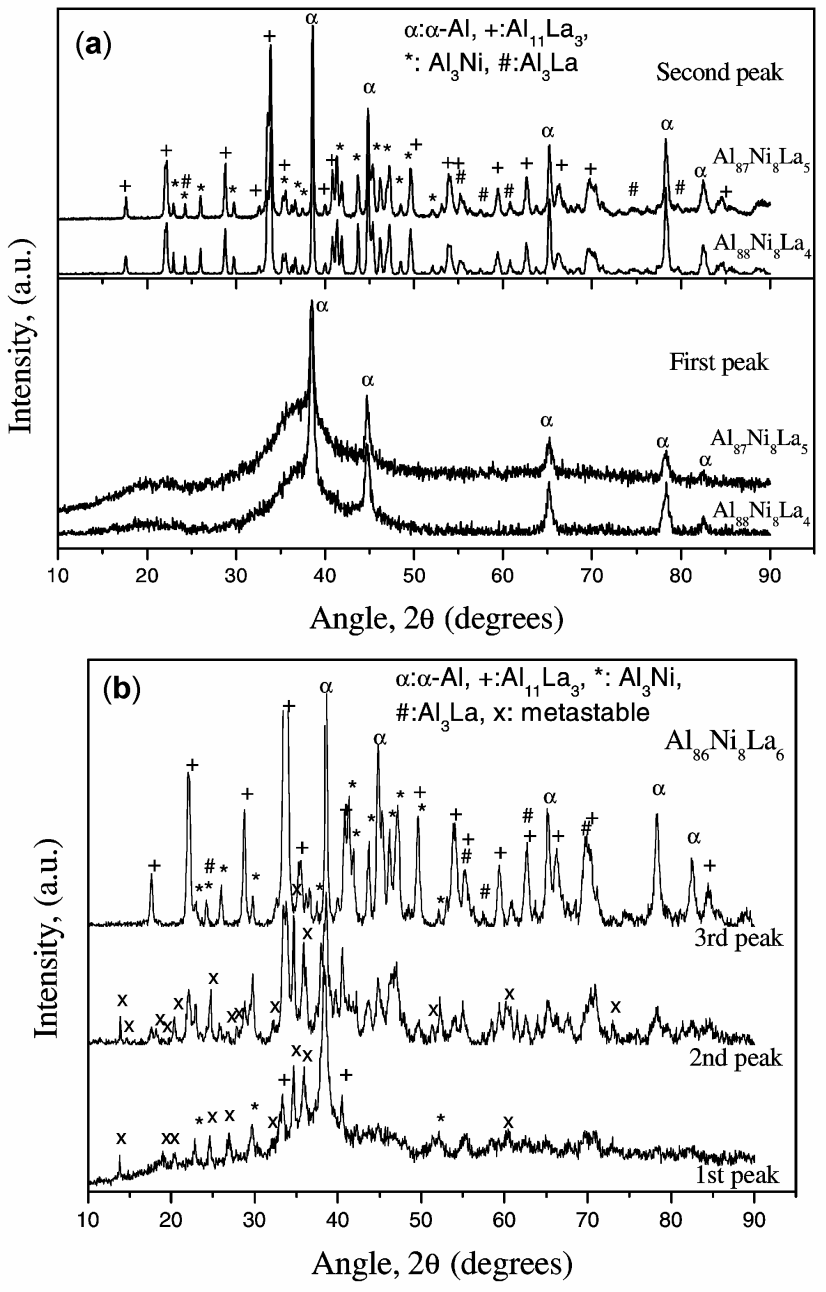

Figure 3. XRD patterns of amorphous Al-Ni-La alloys heated up to the end of crystallization temperatures: (a) $\mathrm{Al}_{88} \mathrm{Ni}_{8} \mathrm{La}_{4}$ and $\mathrm{Al}_{87} \mathrm{Ni}_{8} \mathrm{La}_{5}$ and (b) $\mathrm{Al}_{86} \mathrm{Ni}_{8} \mathrm{La}_{6}$.

were heated in the DSC up to the end of their peaks. All the samples were heated up to the respective crystalliza- tion stages at a rate of $40 \mathrm{~K} / \mathrm{min}$. The XRD patterns of all the corresponding samples are shown in figures 3 and 4 . Figure 3(a) shows that the first crystallization stage in $\mathrm{A} 84$ and A85 alloys is due to the formation of $f c c-\mathrm{Al}$. The second crystallization stage in these alloys is due to formation of $\mathrm{Al}_{11} \mathrm{La}_{3}, \mathrm{Al}_{3} \mathrm{La}$ and $\mathrm{Al}_{3} \mathrm{Ni}$ (figure 3a). In A86 alloy, the first crystallization stage is due to the formation of mainly an unknown metastable phase, $f(c-\mathrm{Al}$ and a small amount of $\mathrm{Al}_{11} \mathrm{La}_{3}$ and $\mathrm{Al}_{3} \mathrm{Ni}$ (figure $3 \mathrm{~b}$ ). The second crystallization stage is due to formation of $\mathrm{Al}_{11} \mathrm{La}_{3}$, $\mathrm{Al}_{3} \mathrm{La}$ and $\mathrm{Al}_{3} \mathrm{Ni}$ from the remaining amorphous matrix and their growth. The third crystallization stage is due to transformation of metastable phases into stable phases probably of $\mathrm{Al}, \mathrm{Al}_{11} \mathrm{La}_{3}$ and $\mathrm{Al}_{3} \mathrm{Ni}$ phases. In case of $\mathrm{A} 66$ alloy, the first crystallization stage is due to formation of both $f c c-\mathrm{Al}$ and a metastable phase (figure $4 \mathrm{a}$ ). The Bragg angles of the latter phase do not match either with $f c c-\mathrm{Al}$ or with any known binary or ternary compound of $\mathrm{Al}, \mathrm{Ni}$ and La. In A67 alloy, formation of $f c c-\mathrm{Al}$ was not detected in the first crystallization stage. Instead, only the metastable phase was observed. Analysing the patterns using the programme 'powder cell' and Rietveld refinement (Rietveld 1969), best agreement with respect to position and intensity of the reflections is achieved for a bodycentred cubic $(b c c)$ phase with a lattice parameter of $0.663 \mathrm{~nm}$. Since, the intensity of the diffraction peaks corresponding to the metastable $b c c$ phase is high in comparison to the remaining halo or the $f c c$-Al phase, it is reasonable to presume that the phase contains a significant amount of an element with a higher atomic number, i.e. La. The second crystallization stage in A66 and A67 alloys is due to formation of $\mathrm{Al}, \mathrm{Al}_{11} \mathrm{La}_{3}$ and $\mathrm{Al}_{3} \mathrm{Ni}$ phases (figure $4 b$ ).

\subsection{Isochronal microhardness}

Figure 5 shows the variation of microhardness with temperature. Different ribbons were annealed for $10 \mathrm{~min}$ at di- 
fferent temperatures starting from room temperature to $480^{\circ} \mathrm{C}$. The hardness values shown in figure 5 are the average of about 10 measurements on each sample and the corresponding errors are shown for each data point. The highest hardness values were detected at around $290^{\circ} \mathrm{C}$ for A66 and A85 alloys and at around $270^{\circ} \mathrm{C}$ for $\mathrm{A} 67$ and A86 alloys (the hardness graph for A67, A66 and A84 alloys are not shown here).

\subsection{TEM studies}

Figure 6 shows the representative TEM selected area diffraction (SAD) pattern of as melt-spun A85 alloy. In accordance with the XRD results no appreciable contrast revealing crystals is seen. The representative TEM image obtained from A85 ribbon, annealed at $290^{\circ} \mathrm{C}$ for $10 \mathrm{~min}$, is shown in figure $7 \mathrm{a}$. In figure $7 \mathrm{a}$, the $\mathrm{SAD}$ pattern shows a broad ring of intensity stemming from the amorphous matrix and rings of diffraction peaks caused by precipitation in amorphous matrix. The dark-field (DF) image was obtained by placing the aperture on the part of
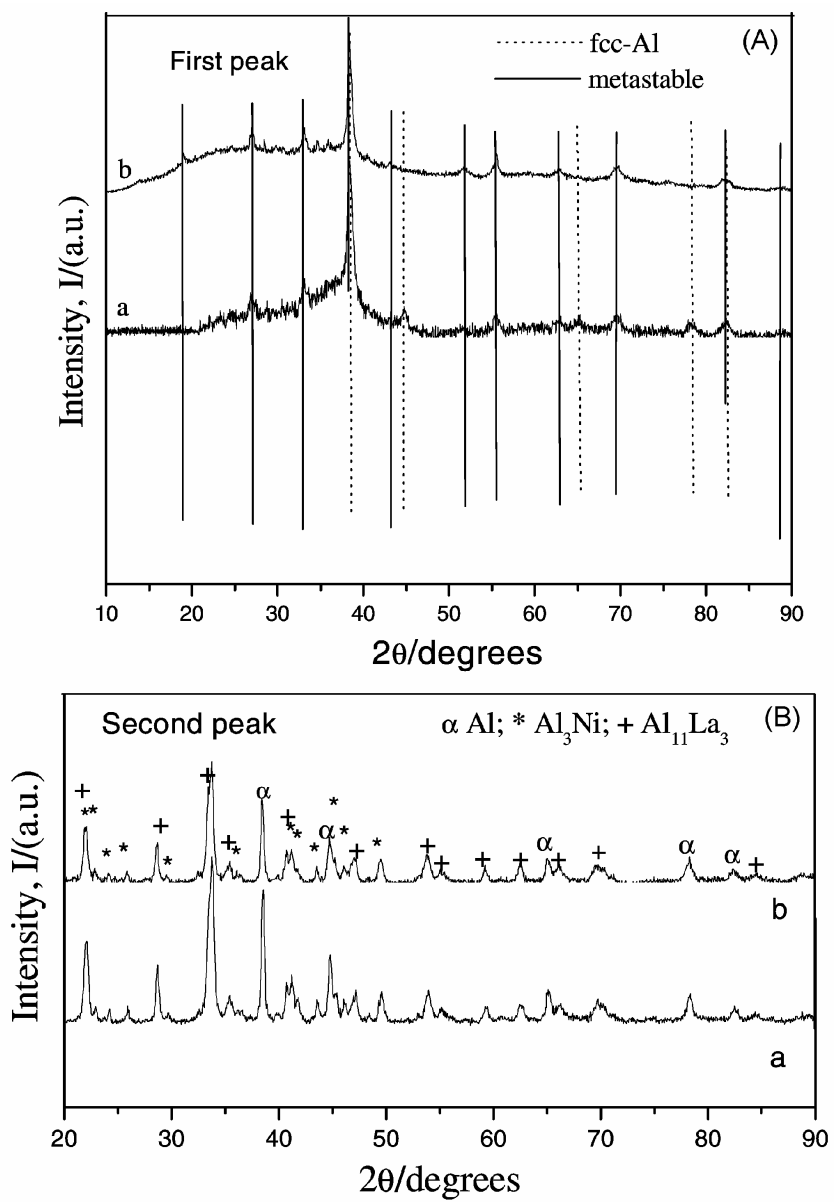

Figure 4. XRD patterns of Al-Ni-La alloys heated up to the end of crystallization temperatures (A) $\mathrm{Al}_{88} \mathrm{Ni}_{6} \mathrm{La}_{6}$ and (B) $\mathrm{Al}_{87} \mathrm{Ni}_{6} \mathrm{La}_{7}$. the diffuse ring as well as the $\{111\}$ and $\{200\}$ diffraction rings. Therefore, $\mathrm{Al}$ precipitates are visible in the image either as bright (in contrast) or dark (out of contrast) patches. From the diffraction rings lattice constant was found to be $0.405 \mathrm{~nm}$. The size of precipitates ranges from a few nanometres to about $40 \mathrm{~nm}$ for large conglomerates. Figure $7 \mathrm{~b}$ shows the TEM dark field image from A85 ribbon annealed at $300^{\circ} \mathrm{C}$ for $10 \mathrm{~min}$. The inset depicts the corresponding $\mathrm{SAD}$ pattern, which reveals a large set of diffraction rings but no indication for an amorphous phase. The size of the precipitates ranges between about 20 and $80 \mathrm{~nm}$.

\section{Discussion}

The materials obtained by melt spinning appear to be amorphous in XRD studies. In spite of this observation,

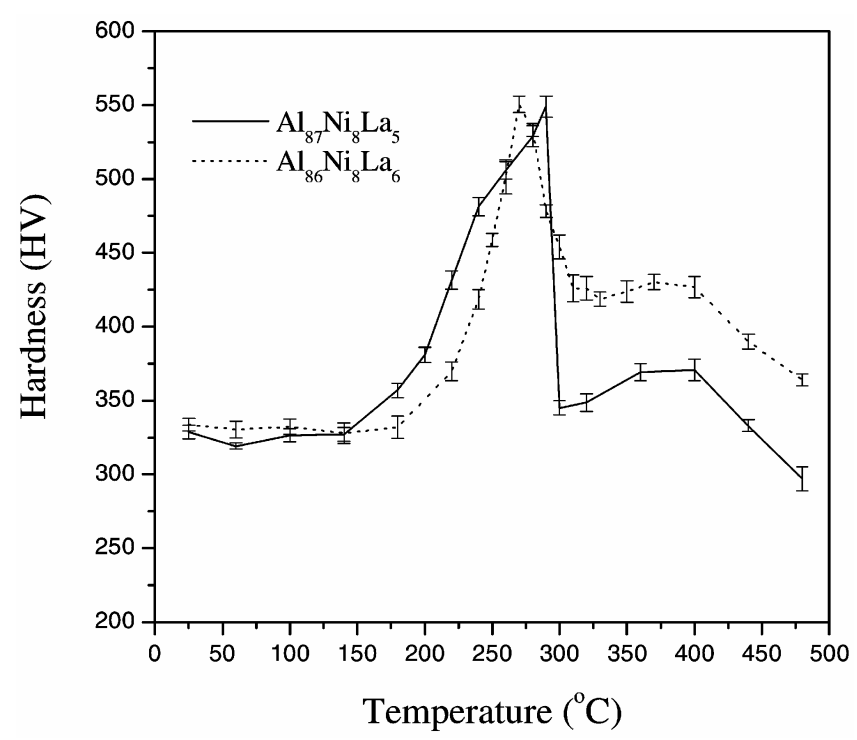

Figure 5. Isochronal microhardness evolution of different $\mathrm{Al}_{92-x} \mathrm{Ni}_{8} \mathrm{La}_{x}$ ribbons. The samples were annealed for $10 \mathrm{~min}$ at each measurement temperature.

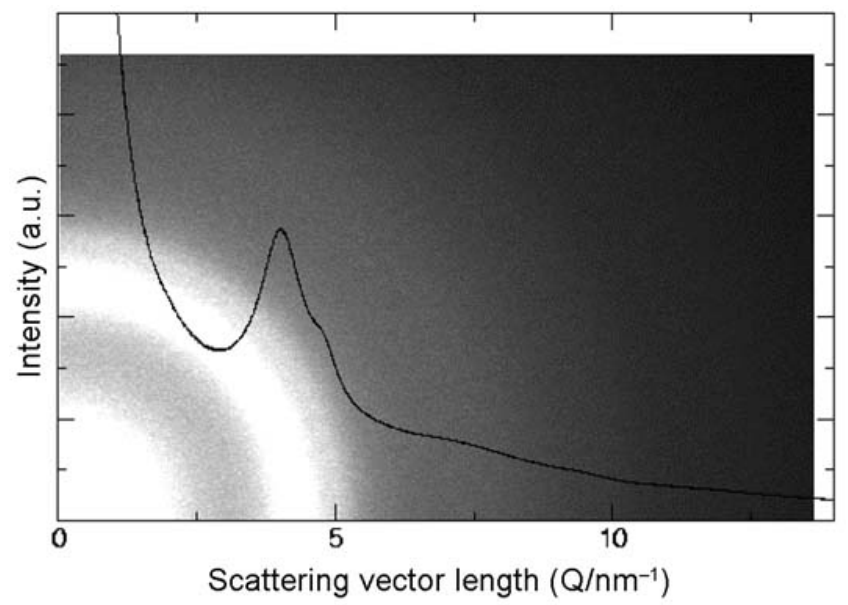

Figure 6. Representative TEM SAD pattern of a as-melt-spun A85 specimen. 
DSC does not show clear glass transition temperature $\left(T_{\mathrm{g}}\right)$, except for the A86 alloy (figure 2). The reason may be that $T_{\mathrm{g}}$ is hidden underneath the first crystallization stage. Accurate measurement of $T_{\mathrm{g}}$ could be done by using temperature modulated DSC (TMDSC) which will separate the reversible heat flow and non-reversible heat flow from the total heat flow (Lu et al 2004). Alloy A86 showed clear glass transition temperature at all heating rates due to higher first crystallization peak temperature, $T_{\mathrm{P} 1}\left(268^{\circ} \mathrm{C}\right)$, than the $T_{\mathrm{g}}\left(248^{\circ} \mathrm{C}\right)$. The enthalpy associated with the glass transition is around $1.9 \mathrm{~J} / \mathrm{g}$ when the sample is heated at $40 \mathrm{~K} / \mathrm{min}$. All the alloys showed (figure 1) a small pre-peak at $2 \theta=15-24^{\circ}$. The observation of a prepeak is an evidence of either for chemical short-range order in the sense of compound-forming behaviour (Steeb and Lamparter 1984) or for the presence of clusters constituted of unlike atoms (Hoyer and Jodicke 1995).
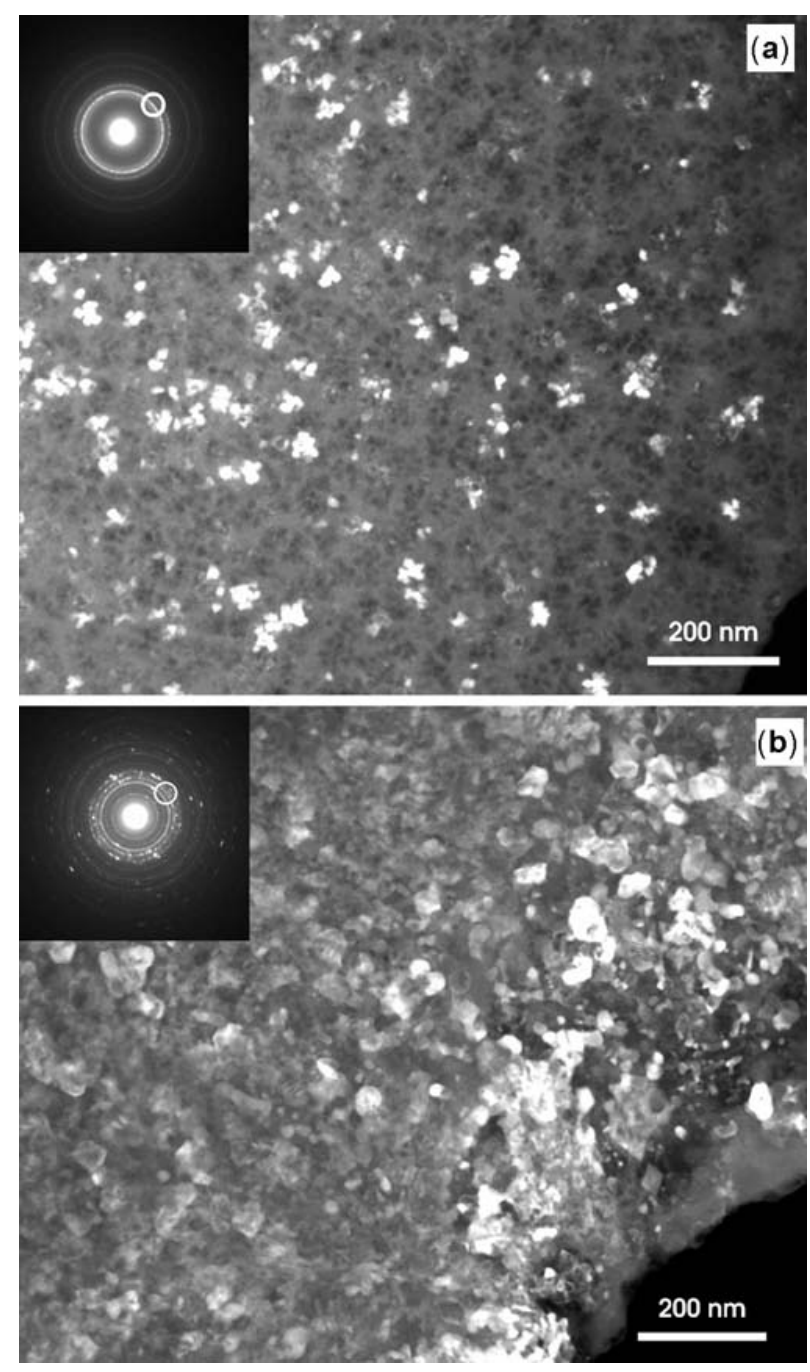

Figure 7. TEM dark field image and inset $\mathrm{SAD}$ of $\mathrm{A} 85$ alloys annealed for ten minutes: (a) $290^{\circ} \mathrm{C}$ and (b) $300^{\circ} \mathrm{C}$. Circle on $\mathrm{SAD}$ patterns show the position from where dark field was taken.
Schmidt et al (2001) reported that the development of a pre-peak monitor changes in the short-range order between the atoms. We recently also observed the presence of small clusters or at least concentration fluctuations on a nanometre scale in as melt spun alloys by small angle neutron scattering (Sahoo et al 2005). Thus, the compound-forming tendency cannot be excluded in the present as melt spun alloys.

The peak of the first crystallization stage is distinctly asymmetric with a tail towards higher temperature (figure 2 ). The first crystallization peak temperature increases and the second crystallization peak temperature decreases with increasing $\mathrm{La}$ content for a fixed Ni composition. This fits into the general tendency that higher Al contents lower thermal stability of Al-Ni-La alloys. The observed changes of the first and second crystallization temperatures are in good agreement with the data for other Al$\mathrm{Ni}-\mathrm{La}$ alloys in the literature (Inoue 1998; Gangopadhyay and Kelton 2000). XRD analyses of specimens annealed to about the end of crystallization events as observed by DSC (figure 2) revealed two-stage crystallization pathways for all the ribbons except A86 that shows threestage crystallization pathways. The $f c c-\mathrm{Al}$ formed during the first stage of crystallization in alloys A84 and A85 yields a lattice constant of $405.4 \mathrm{pm}$, which is nearly same as of pure $\mathrm{Al}(404.9 \mathrm{pm})$. The representative crystallization peak temperatures in a ternary diagram are shown in figure 8 . The grey shaded hexagons show the temperatures from our measurements whereas the open hexagons contain values from the literature. In the hexagon, the lower value indicates first crystallization peak temperature and the upper value indicates the second crystallization peak temperature. The dashed line approximately divides two regions of different crystallization behaviour. The evolution of first peak temperature shows a change in slope for all heating rates at La concentration of $\geq 6$ at. $\%$. The overall tendency is that the first peak temperature increases while the second peak temperature is reduced with increasing $\mathrm{La}$ and $\mathrm{Ni}$ contents (including the binary Al-La alloys). It can be seen that there is a

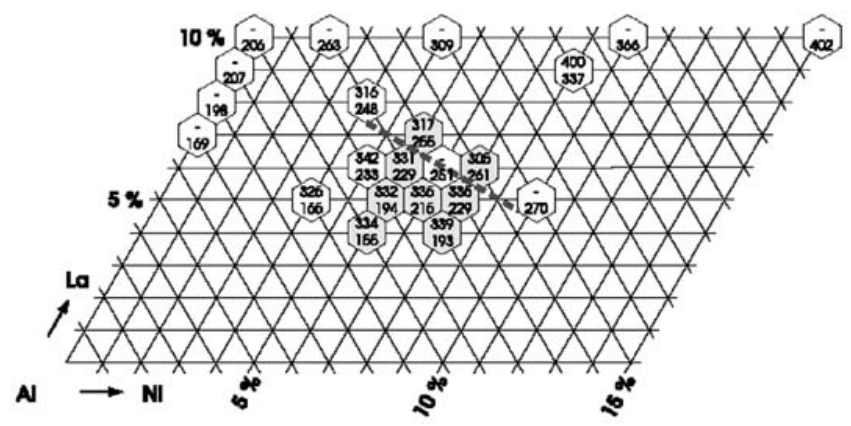

Figure 8. Representation of crystallization peak temperatures in a ternary diagram of $\mathrm{Al}-\mathrm{La}$ binary and $\mathrm{Al}-\mathrm{Ni}-\mathrm{La}$ ternary alloys. 
jump in crystallization temperature whenever the line drawn in figure 8 is crossed.

The as melt-spun ribbons show higher hardness with increasing La concentration (figure 5) indicating different initial microstructures of the ribbons. The different manner of evolution of heat flow with time at a constant temperature also indicated different structural states of the ribbons. Hardness does not change much from room temperature to about $150^{\circ} \mathrm{C}$. This is due to the fact that the microstructure does not change appreciably as these glasses are thermally stable at lower temperatures. Thereafter, a sharp increase of hardness with increasing temperature is observed which is caused by crystallization of fcc-Al (for low La content) or metastable phase (for high La content) leading to precipitation strengthening of the material. At the point where highest hardness is observed, the matrix is still amorphous (figure 7a). The solid solubility of $\mathrm{Ni}$ and $\mathrm{La}$ in $\mathrm{Al}$ at the equilibrium eutectic temperature of each binary system is about 0.01 at.\% (Gschneider and Calderwood 1986; Singleton et al 1986). Rapidly solidified Al-rich Al-Ni alloy extends the solid solubility limit of $\mathrm{Ni}$ in $\mathrm{Al}$ from 0.01 at.\% to as much as 7.7 at.\% (Singleton et al 1986). Therefore, with the crystallization and growth of $\mathrm{Al}$ particles from the rapidly solidified amorphous alloys, $\mathrm{Ni}$ and $\mathrm{La}$, are rejected and the remaining amorphous matrix gets richer in solute elements leading to stable amorphous matrix. It is reported that rare earth elements diffuse much slower in $\mathrm{Al}$ than in $\mathrm{Ni}$ and $\mathrm{Fe}$ (Hono et al 1995). The diffusivity of La in these alloy systems may be lower than those of Al and $\mathrm{Ni}$ by orders of magnitude because of its larger atomic radius. Hence, during the growth of $\mathrm{Al}$ particles, the rejected $\mathrm{La}$ atoms are enriched at the $\mathrm{Al} /$ amorphous interface and the interface must reject La for further growth. This would effectively slow down the growth of Al particles. With temperature, the increase in diffusivity of the elements yields additional nucleation and a substantial increase in the initial particle growth rate. Crystallization at higher temperatures (above $290^{\circ} \mathrm{C}$ for A85 alloy), leading to substantial growth of $\mathrm{Al}$ particles (figure 7a) and to decomposition of the amorphous matrix leading to precipitation of intermetallic particles (mainly, $\mathrm{Al}_{11} \mathrm{La}_{3}$ and $\mathrm{Al}_{3} \mathrm{Ni}$ ) from the matrix (figure 7b), results in a sharp drop of hardness. The TEM DF image shows (figure 7b) that the precipitates are bigger in size compared to that for the specimen annealed at $290^{\circ} \mathrm{C}$ and also shows a wide range of sizes. With the progress of crystallization hardness increases again due to the increased volume fraction of crystallized intermetallic particles. Later on, the decrease of hardness with higher temperature is due to coarsening of the particles (figure not shown). Microhardness evolution with temperature in A86 alloy is different from other alloys because of the formation of different kinds of crystallites during the various stages of crystallization. The slower drop of hardness after $270^{\circ} \mathrm{C}$ is due to transformation of metastable phases to $f c c-\mathrm{Al}$ and intermetallic phases. In the fully crystallized state hardness increases with La content due to an increased amount of intermetallic phases in the matrix. The plastic deformation in such type of metallic glasses could be explained by studying the morphological characteristics of the indentation deformation zones. In this context, a good number of literatures are available that deal with the mechanical behaviour, mainly plastic deformation, in amorphous and partially crystallized bulk metallic glasses (Basu et al 2003; Ramamurty et al 2005; Schuh et al 2007).

\section{Conclusions}

The results showed that the variation of La content in Al$\mathrm{Ni}-\mathrm{La}$ alloys has significant influence on the crystallization pathways from amorphous to stable crystalline phases and on the evolution of microhardness with temperature.

DSC and XRD analyses revealed two-stage crystallization pathways for all the ribbons except A86 that shows three-stage crystallization pathways.

The two stages of crystallization in $\mathrm{Al}_{88} \mathrm{Ni}_{8} \mathrm{La}_{4}$ (A84) and $\mathrm{Al}_{87} \mathrm{Ni}_{8} \mathrm{La}_{5}$ (A85) alloy correspond to the formation of fcc-Al and $\mathrm{Al}_{11} \mathrm{La}_{3}, \mathrm{Al}_{3} \mathrm{Ni}, \mathrm{Al}_{3} \mathrm{La}$, respectively. We report the three-stage crystallization in $\mathrm{Al}_{86} \mathrm{Ni}_{8} \mathrm{La}_{6}$ (A86) alloy, which corresponds to formation of metastable phase, fcc-Al, $\mathrm{Al}_{11} \mathrm{La}_{3}, \mathrm{Al}_{3} \mathrm{Ni}$ (first stage), $\mathrm{Al}_{11} \mathrm{La}_{3}, \mathrm{Al}_{3} \mathrm{Ni}, \mathrm{Al}_{3} \mathrm{La}$ (second stage) and decomposition of metastable phase to stable crystalline phases (third stage).

The first crystallization temperature increases while the second one decreases with increasing La concentration.

The higher microhardness with increasing La content indicates different structural state of initial ribbons. The hardness does not change appreciably up to the temperature of $150^{\circ} \mathrm{C}$ indicating the structural stability at lower temperatures. Thereafter, the sharp increase of hardness is due to nanoscale precipitation of primary crystallization product. The rapid fall of hardness in A84 and A85 alloys after $290^{\circ} \mathrm{C}$ and in $\mathrm{A} 86$ alloy after $270^{\circ} \mathrm{C}$ is due to decomposition of amorphous matrix and formation of intermetallic compounds.

\section{Acknowledgement}

The authors wish to thank DST (NSTI) for sponsoring the project, grant. No. SR/S5/NM-78/2002.

\section{References}

Basu J, Nagendra N, Li Y and Ramamurty U 2003 Philos. Mag. 831747

Gangopadhyay A K and Kelton K F 2000 Philos. Mag. A80 1193

Gogebakan M, Warren P J and Cantor B 1997 Mater. Sci. Eng. A226 168

Gschneider Jr K A and Calderwood F W 1986 Binary alloy phase diagram (ed.) T B Massalski (Metals Park, Ohio: American Society for Metals) Vol. 1 
Hono K, Zhang Y, Inoue A and Sakurai T 1995 Mater. Trans. JIM 36 909

Hoyer W and Jodicke R 1995 J. Non-Cryst. Solids 192-193 102

Inoue A 1998 Prog. Mater. Sci. 43365

Kissinger H E 1957 Anal. Chem. 291702

Lu Z P, Liu C T and Li Y 2004 Intermetallics 12869

Ramamurty U, Jana S, Kawamura Y and Chattopadhyay K 2005 Acta Mater. 53705

Rietveld H M 1969 J. Appl. Crystallogr. 265

Sahoo K L, Panda A K, Das S and Rao V 2004 Mater. Letts 58316

Sahoo K L, Wollgarten M, Haug J and Banhart J 2005 Acta Mater. 533861
Schmidt U, Eisenschmidt C, Zahra C Y and Zahra A -M $2001 \mathrm{~J}$. Non-Cryst. Solids 28975

Schuh C A, Hufnagel T C and Ramamurty U 2007 Acta Mater. 554067

Singleton M F, Murray J L and Nash P 1986 Binary alloy phase diagram (ed.) T B Massalski (Metals Park, Ohio: American Society for Metals) Vol. 1

Steeb S and Lamparter P 1984 J. Non-Cryst. Solids 61-62 237

Ye F and Lu K 1999 Acta Mater. 472449

Zhuang Y X, Jiang J Z, Lin Z G, Mezouar M, Crichton W and Inoue A 2001 Appl. Phys. Lett. 79743 